\title{
PERSPECTIVE
}

\section{Myopia: attempts to arrest progression}

\section{S M Saw, G Gazzard, K-G Au Eong, D T H Tan}

Br J Ophthalmol 2002;86:1306-1311

Previous studies have evaluated the efficacy of several interventions to decrease the progression of myopia. These include devices that alter the perception of the visual environment and pharmacological treatments. There is no conclusive evidence thus far that alteration of the pattern of spectacle wear, bifocals, ocular hypotensives, or contact lenses retards the progression of myopia. Several randomised clinical trials have demonstrated that the rate of progression of myopia is lower in children given atropine eye drops than those given placebo. However, atropine is associated with short term side effects such as photophobia and possible long term adverse events including light induced retinal damage and cataract formation. Other more selective antimuscarinic agents such as pirenzipine are presently being evaluated. Further well conducted randomised clinical trials with large sample sizes and adequate follow up designed to evaluate treatments to retard the progression of myopia should be conducted, since the identification of an effective intervention may have a greater public health impact on the burden and morbidity from myopia than the few treatments currently available.

See end of article for authors' affiliations

Dr Seang-Mei Saw

Dr Seang-Mei Saw,
Department of Community, Occupational and Family Medicine, National University of Singapore, 16 Medical Drive, Singapore

117597, Republic of

Singapore:

cofsawsm@nus.edu.sg

Accepted for publication 26 June 2002

.....................
M yopia has been known for more than 2000 years and was first described by the ancient Greeks. ${ }^{12}$ However, despite the recorded use of convex lenses for presbyopia in the late 13th century in Florence, Italy, the correction of myopic refractive error had to await the development of concave lenses in the mid 16th century.

Myopia may be classified as "school myopia" or "adult onset myopia." ${ }^{3}$ School myopia develops during the school age and stabilises around 15-17 years of age, while adult onset myopia develops in young adults. The aetiology, pathogenesis, and treatment of myopia have been hotly debated in the ophthalmic community for decades. ${ }^{4}$ There are several theories on the mechanism of development of myopia arising from disruption of the emmetropisation process. Emmetropisation is achieved when the optical power of the eye matches the axial length, resulting in a focused image of a distant object on the retina without accommodative effort. ${ }^{5}$ It has been proposed that overacting intraocular muscles may result in excessive accommodation and influence emmetropisation. ${ }^{6}$ The two basic mechanisms by which animal myopia may be induced are form deprivation and optical defocus. Form deprivation myopia can be induced by the application of translucent occluders over the animal's eyes. Local retinal effects may occur and the resultant scleral growth modulated by chemicals such as dopamine, growth factors, and muscarinic antagonists. $^{7-9}$ Negative spectacle lenses in chicks induce compensatory axial elongation and myopia. ${ }^{10}$

Suitable therapeutic modalities such as pharmacological interventions and optical corrective devices that may retard the progression of myopia in myopic individuals have been reported. The overwhelming majority of these reports have been cited in optometry and not ophthalmology journals. The optical correction of myopia and optimal strategies to prevent the progression of myopia have been developed and prescribed largely by optometrists. On the other hand, issues regarding the causes and prevention of myopia have only gained interest among ophthalmologists in the recent decade. The objective of this review is to summarise in a comprehensive manner the current evidence for the postulated mechanisms of action, efficacy, and adverse effects of these various treatments to arrest myopia progression.

\section{ALTERATION OF PATTERN OF SPECTACLE WEAR}

When myopia is not corrected, lack of a clear visual image may lead to "form deprivation myopia." ${ }^{\prime 1}$ Conversely, correcting a child's myopia with negative lenses may result in compensatory aberrant eye growth and the development of myopia. ${ }^{10}$ Animal experiments have shown that compensatory changes in the axial length of an eye may occur in response to error signals from lens induced defocus. ${ }^{10} 12$ In a non-randomised clinical trial evaluating part-time distance spectacle wear in the United States, 43 myopes were categorised into four treatment groups: (a) full time spectacle wear, (b) wear for distance viewing and then a switch to full time wear, (c) wear for distance viewing only, and (d) non-wear. Over a period of 3 years, there were no significant differences in refractive shifts as measured by noncycloplegic distance retinoscopy between the treatment groups. ${ }^{13}$ In a non-masked randomised clinical trial of 240 myopic schoolchildren aged 9-11 years in Finland, children were randomised to (a) minus lenses with full correction for continuous use, (b) minus lenses with full correction to be used for distance vision only, and (c) bifocal lenses. There were no significant differences in the rate of myopia progression in the different groups after 3 years. ${ }^{14}$

Distance undercorrection may reduce accommodative focus. ${ }^{15}$ Straub compared fully corrected 
and undercorrected myopic teenagers and concluded that full correction does not have an effect on the progression of myopia. ${ }^{16}$ However, this trial was not randomised. In another small non-randomised trial by Tokoro and Kabe, 11 subjects who wore full correction had a mean rate of progression of -0.83 dioptre (D) per year, compared to a mean rate of -0.47 $\mathrm{D}$ per year in five subjects who had undercorrection $(\mathrm{p}<0.01){ }^{17}$

\section{BIFOCALS AND MULTIFOCALS}

The reduced accommodative response of myopic children to near objects may be associated with retinal blur and possible uncoordinated eye growth. ${ }^{18}$ Bifocal lenses may reduce accommodative demand during near work and thus decrease the rate of progression of myopia. However, bifocals may not control accommodation at all distances since there are only two focal zones (a distance zone and a near zone) and there may be slightly out of focus retinal images at other distances. ${ }^{19}$

Optometrists have been using bifocal lenses as a possible treatment for myopia since the 1940s. In 1955, Warren prescribed lenses with $\mathrm{a}+1.25 \mathrm{D}$ addition in an 18 year old myopic college student. ${ }^{20}$ However, no results were reported. A large number of clinical trials and retrospective studies that have evaluated bifocal lenses are severely limited by small sample size, lack of a control group, lack of randomisation in the allocation of treatment groups or a combination of these deficiencies. $^{21-29}$ Furthermore, bifocal lenses may be less cosmetically acceptable, are difficult to adapt to, and compliance with spectacle wear may be a problem. In addition, children may not always use the lower segment of the lens for reading. Recently, there have been several well designed randomised clinical trials of bifocal lenses conducted in children in the United States, Finland, and Denmark. ${ }^{30-33}$ The bifocal trials tested a range of vision additions $(+1.00 \mathrm{D}$ to $+2.00 \mathrm{D})$ and the sample sizes of the trials varied from 32 to 240. In all these trials, there were no significant differences in the myopia progression rates.

Progressive addition multifocal lenses are more cosmetically acceptable and allow children to have clear vision at all distances without adjustment of the focal mechanism of the eye. In young myopes, however, the progressive addition lens must be fitted very high to facilitate the use of the segment for reading. In a clinical trial conducted by Leung and Brown in Hong Kong, 22 children were assigned to wear progressive lenses with $+1.50 \mathrm{D}$ addition, 14 to lenses with $+2.00 \mathrm{D}$ addition, and 32 to single vision lenses. The mean progression rate of myopia was $-3.73 \mathrm{D}$ for the children assigned to $+1.50 \mathrm{D}$ additions, $-3.67 \mathrm{D}$ for children wearing $+2.00 \mathrm{D}$ additions, and $-3.67 \mathrm{D}$ for children wearing single vision lenses $(p<0.001)$. However, the assignment was not random: subjects with even case record numbers were placed in the progressive lenses group, while subjects with odd case record numbers were placed in the single vision lenses group. ${ }^{19} \mathrm{~A}$ Taiwanese randomised clinical trial by Shih and colleagues showed a non-significant reduction of the progression of myopia (mean myopia progression -1.19 D per year in multifocal group versus $-1.40 \mathrm{D}$ per year in single vision group) in 227 myopic children aged 6-12 years after $1 \frac{1 / 2}{2}$ years. ${ }^{34}$ The Correction of Myopia Evaluation Trial (COMET) is a large ongoing 3 year multicentre randomised, double masked trial evaluating the effect of progressive addition lenses versus single vision lenses in 469 myopic children (spherical equivalent between -1.25 and $-4.50 \mathrm{D}$ ) aged 6-11 years in the United States. ${ }^{35}{ }^{36}$ The results from this trial may provide new evidence for the efficacy of multifocal lenses.

\section{CONTACT LENSES}

Contact lenses have a long history of use as optical correction since their introduction by Eugen Fick in $1888 .{ }^{37}$ Contact lenses may increase peripheral vision, provide cosmetic benefits, and promote more outdoor activity. However, potential complications of contact lens use include allergic conjunctivitis, corneal infiltrates, and infective keratitis, and contact lens hygiene compliance may be a problem in less responsible children.

In infant primates wearing minus contact lenses, compensatory ocular growth may lead to functional myopia. ${ }^{38}{ }^{39} \mathrm{~A}$ large number of reports on the efficacy of various types of contact lenses (silicone acrylate contact lenses, hydrophilic contact lenses, hydrogel lenses) were not randomised, had small sample sizes, and high dropout rates. ${ }^{40-47}$ In a randomised clinical trial of the efficacy of soft contact lenses in 175 children by Horner and associates in the United States, there was no significant difference in the rate of progression of myopia between the contact lens $(-0.36 \mathrm{D}$ per year) and control group $(-0.30 \mathrm{D}$ per year $)$. $^{48}$

Morrison in 1956 fitted 1021 myopic children (7-9 years) flatter than the flattest curvature with polymethyl methacrylate (PMMA) hard contact lenses, thus altering the shape of the cornea. ${ }^{49}$ However, there were hypoxia related corneal changes. New rigid gas permeable lenses with high oxygen permeability are a suitable and safer alternative. ${ }^{45}$ The potential mechanisms of action of rigid contact lenses include transient flattening of the cornea, and improved quality of the retinal image with reduced peripheral image "blur." Perhaps rigid contact lenses may even retard axial elongation. However, the permanence of these mechanisms of action is still unknown.

In the 3 year Houston study of rigid gas permeable contact lenses, 100 myopic children aged 8-13 years were fitted with Paraperm oxygen plus contact lenses and were compared with 20 spectacle wearers. The average progression of myopia was significantly different: $0.48 \mathrm{D}$ per year for rigid contact lens wearers compared with $-1.53 \mathrm{D}$ per year for spectacle wearers. ${ }^{50}$ However, the allocation of treatment was not randomised. It was also observed that approximately half of the effect of rigid gas permeable contact lenses was due to transient corneal flattening. In a non-randomised study of 45 rigid contact lens wearers and 45 spectacle wearers in Singapore 10 year old children, the mean increase in myopia over a 3 year period of spectacle wearers was $-2.3 \mathrm{D}$ in contrast with $-1.3 \mathrm{D}$ for contact lens wearers $(\mathrm{p}<0.05) .{ }^{51}$ No major adverse events were noted. However, in a more recent and larger randomised clinical trial of rigid contact lenses with 383 Singapore children aged 6-12 years over 2 years, there was no significant differences in the rate of progression of myopia or axial length in the two groups (Katz J et al, submitted for publication)

\section{ORTHOKERATOLOGY}

The technique known as orthokeratology has been practised for decades: the cornea is flattened by fitting progressively flatter rigid contact lenses until the corneal shape is sufficiently altered to achieve myopia reduction. ${ }^{52}$ The temporary alteration of corneal shape and hence correction of myopia allows for periods of clear unaided vision during the day without the use of lenses, but requires constant use of retainer lens, usually worn overnight, with the potential complications of infective keratitis relating to closed eye contact lens wear. However, corneal flattening does not treat the intrinsic cause of myopia and may be a remedy rather than a cure. In the Berkeley Orthokeratology Study, 80 subjects were randomised to orthokeratology or a control group wearing contact lenses fitted in the standard clinical manner. There was a significantly larger reduction in myopia for the patients randomised to orthokeratology, but the reduction did not persist after orthokeratology. ${ }^{52}$ Thus, orthokeratology has little clinical value for the retardation of myopia progression. 


\section{ATROPINE AND PIRENZIPINE EYE DROPS}

Atropine is an alkaloid from the deadly nightshade Atropa belladonna and has several proposed mechanisms of action. Firstly, atropine may block accommodation and reduce the putative effects of excessive accommodation on the progression of myopia. ${ }^{11}$ Secondly, atropine is a non-selective muscarinic antagonist and it has been observed that in animals treated with atropine, form deprivation myopia may be suppressed with retardation of axial length elongation. ${ }^{53-55}$ Atropine also affects dopamine neurotransmitter release from cellular stores and thus may influence retinal signals that control the growth of the eye. ${ }^{56}$ Thirdly, atropine may reach sufficient levels in the bloodstream to have systemic effects. Atropine suppresses growth hormone secretion from the pituitary gland which could disturb normal eye growth. ${ }^{57} 58$

The first reports of atropine treatment for myopia were by Wells in the 19th century. ${ }^{3}$ In 1979, Bedrossian evaluated the effect of $1 \%$ atropine ointment instilled once at night in one eye for 1 year with the fellow eye as the control in a non-randomised trial. After 1 year, treatment was switched to the fellow eye, and the control eyes showed significant increases in the rate of myopia. ${ }^{59}$ However, the fellow eye may not be suitable as a control as there may be systemic residual effects of atropine on the fellow eye. Several other studies have evaluated topical atropine therapy but unfortunately had sufficient methodological flaws to preclude any reliable conclusions. ${ }^{15}{ }^{16}{ }^{60-67}$ A range of concentrations (0.1\% to $1 \%$ ) of atropine eye drops were tested in three randomised clinical trials of schoolchildren in Taiwan and the rate of progression of myopia in the atropine group was significantly lower compared with the control group. ${ }^{3468}{ }^{69}$ Higher doses of atropine ( $1 \%$ atropine) may, however, be associated with an increased incidence and severity of local effects (examples include mydriasis, photophobia, blurred vision, allergic dermatitis) and systemic effects ${ }^{3468}{ }^{69}$; lower doses of atropine $(0.5 \%$, $0.25 \%, 0.1 \%$ ) were better tolerated. ${ }^{68}$ The long term side effects of atropine eye drops in children are relatively unknown and there may be a risk of long term ultraviolet light related retinal damage and cataract formation as a result of chronic pupillary dilatation. ${ }^{64}$

Pirenzipine is a relatively selective Ml subtype muscarinic receptor antagonist and $\mathrm{Ml}$ receptors are found in the ciliary processes. ${ }^{70-74}$ In both avian and mammalian models, pirenzipine has been shown to block form deprivation myopia and axial elongation. ${ }^{75-77}$ The tolerability of pirenzipine gel formulation was tested in a double masked placebo controlled randomised clinical trial of children aged 9-12 years in the United States. ${ }^{78}$ The subjects received pirenzipine $0.5 \%$ for the first week, $1.0 \%$ for the second week, and $2.0 \%$ for an additional 2 weeks. Another study of 49 adult male volunteers found that pirenzepine ophthalmic gel at $0.5 \%, 1.0 \%$, and $2.0 \%$ was well tolerated, produced minimal mydriasis, and the only adverse event noted was a transient unilateral loss of visual acuity in one patient which recovered by the next visit. ${ }^{79}$ Although randomised clinical trials are currently in progress, efficacy data are not yet available.

\section{TROPICAMIDE EYE DROPS}

Tropicamide is a short acting cycloplegic agent that relaxes ciliary muscle tone and blocks accommodation. In a study of 61 children aged $6-16$ years given $0.4 \%$ tropicamide eye drops, the average degree of myopia was reduced from $-0.85 \mathrm{D}$ to $-0.62 \mathrm{D}^{80}$ There was, however, no control group. A matched pair design of 25 twins in the United States given a combination of $1 \%$ tropicamide eye drops with bifocals against single vision spectacles, showed no significant differences in myopia progression after $31 \frac{1}{2}$ years of follow up. ${ }^{81}$ Tropicamide has a shorter half life than atropine and its associated side effects are correspondingly more transient. Studies of several thousand applications of tropicamide showed no adverse experiences. ${ }^{662}$ However, the shorter duration of action requires more frequent administration for continual blockade of accommodation, and therefore is less convenient.

\section{OCULAR HYPOTENSIVES}

It has been hypothesised that the increase in eye size in myopia may be due to passive stretching of the sclera because of increased intraocular pressure from an increase in vitreous chamber volume. ${ }^{83}$ It has been postulated that excessive accommodation or convergence may increase intraocular pressures, producing an increased force in the sclera, causing axial elongation. However, previous studies have found that patients who accommodated at near had slightly lower or similar intraocular pressures. ${ }^{84-87}$ Perhaps during accommodation, traction is exerted on the scleral spur resulting in the opening of the trabecular network and increased aqueous outflow. In addition, there is little conclusive evidence that myopic children have higher intraocular pressures than their emmetropic counterparts. ${ }^{88}$

Ocular hypotensives that have been assessed for their effect on myopia progression include labetalol and timolol ( $\beta$ adrenergic blockers) ${ }^{89}$ Previous studies have found that timolol maleate may affect sympathetic innervation to the ciliary muscles and shift the resting position of accommodation..$^{90}$ When labetalol eye drops $(0.5 \%$ or $0.25 \%)$ were given twice daily to 50 Japanese subjects, aged 6-14 years old for 2-4 months, a $0.25 \mathrm{D}$ improvement in $68 \%$ of the eyes was observed ${ }^{80}$ The results of these studies are difficult to interpret because there was no control group. Several other studies also did not include a control group or were not randomised. ${ }^{92}{ }^{93} \mathrm{~A}$ randomised clinical trial of timolol $0.25 \%$ against spectacles in 150 Danish children showed no significant difference in the progression of myopia in the two groups $(-0.59 \mathrm{D}$ per year in the timolol group versus $-0.57 \mathrm{D}$ per year in the single vision group) after 2 years. ${ }^{33}$ Other ocular hypotensives that have been evaluated in non-randomised clinical trials include adrenergic agents such as adrenaline (epinephrine) and parasympathomimetic agents such as pilocarpine. ${ }^{394}$ In general, there is a lack of evidence supporting the hypothesis that decreasing intraocular pressure may retard myopia progression and there may be risks of significant side effects such as bronchospasm in susceptible individuals. ${ }^{95} 96$

\section{BIOFEEDBACK VISUAL TRAINING}

As early as the 1940s, Bates proposed that overaction of extraocular muscles may lead to changes in accommodation. ${ }^{97}$ Bates's system of eye exercises are administered by repeated testing with the same Snellen chart daily. Visual training may change the way the autonomic nervous system regulates the accommodative process. ${ }^{98}$ This occurs through a learning process possibly mediated by the sympathetic nervous system. However, the efficacy of this treatment has not been proved in randomised clinical trials. Trachtman postulated that the ciliary muscle action responsible for refractive error change is susceptible to biofeedback training. ${ }^{99}$ Several other non-randomised studies have evaluated "biofeedback visual training" and behavioural techniques to improve visual acuity and reduce myopia. ${ }^{100-105}$ If there were any improvement in visual acuity, it was not clear whether it was attributable to biofeedback visual training or, in fact, to a learning effect after several repeated measures of visual acuity. ${ }^{101}$ There is currently no conclusive evidence that biofeedback visual training is effective in retarding myopia. 


\section{TRADITIONAL CHINESE INTERVENTIONAL TREATMENTS}

Facial "Qi Qong" eye exercises were created in the 1950s in China. It was postulated that massaging the various acupuncture pressure points around the eye improves venous blood circulation, relaxes the muscles, and reduces eye strain. These eye exercises are part of the school routine in many parts of China, and teachers guide the children in the performance of these eye exercises as often as twice a day for 10 minutes. The evidence from two non-randomised studies conducted in Singapore and Taiwan were inconclusive. ${ }^{106}{ }^{107}$ In another nonrandomised clinical trial of 242 adolescent eyes in 295 people in Beijing, small pieces of adhesive pressure plaster grains of Semen impatiens were evaluated. Significant treatment effects were claimed. ${ }^{108}$

\section{CLINICAL IMPLICATIONS AND FUTURE STUDIES}

Despite the extensive efforts that have been made to identify interventions that may decrease the progression of myopia, many previous studies were often limited by methodological flaws. Large scale high quality masked randomised clinical trials are necessary to test the efficacy of any treatment. We would like to propose two high quality masked randomised clinical trials to evaluate atropine eye drops and bifocals or multifocals. In the first proposed atropine trial (the control group is prescribed placebo eye drops), it is important to mask the subjects and alleviate potential side effects of atropine by the prescription of photochromatic lenses to block ultraviolet light. If atropine eye drops are administered in both eyes and there is reduced accommodative ability, multifocal lenses should also be prescribed. The second proposed trial is the evaluation of multifocal lenses in a double masked randomised trial where both multifocal and ordinary prescription lenses appear exactly the same. The patient should be advised not to visit other optometrists or ophthalmologists to find out the type of lenses the children have been prescribed. In addition, an independent and separate team could be employed to perform the refractions. It is not possible at present, however, to conduct masked trials to evaluate the effect of contact lenses to retard the progression of myopia, because it is not possible to mask the control group.

An evidence based review has shown that there are currently few $(\mathrm{n}=10)$ high quality, completed, well conducted, masked randomised clinical trials that have evaluated the efficacy of interventions to retard the progression of myopia. ${ }^{109}$ At present, there are four published randomised clinical trials that have evaluated atropine eye drops, but only three trials (two in Taiwan and one in the United States) were masked. ${ }^{34} 6^{81} 109$ Five randomised clinical trials that evaluated the role of bifocals have been published thus far, but only two trials conducted by Fulk et al in the United States were masked. ${ }^{30}{ }^{31} 109$ There are no masked trials to evaluate the efficacy of contact lenses.

To date, atropine eye drops appear the most promising. Their use significantly decreased the progression of myopia in Taiwanese children in several studies. ${ }^{34}{ }^{68}{ }^{69}$ However, these studies need to be replicated in other populations with similarly high baseline myopia progression rates and possible serious long term side effects evaluated in careful studies with longer follow up. The results of trials evaluating pirenzipine are keenly awaited, and it remains to be seen whether the potential use of pirenzipine to retard myopia progression with minimal side effects will be realised. The results of the clinical trial by Fulk et al, ${ }^{31}$ on bifocal lenses are encouraging, but larger double masked randomised clinical trials are needed to confirm its efficacy. Other interventions such as tropicamide eye drops, ocular hypotensives, or traditional Chinese treatments need further evaluation in well conducted randomised trials. The identification of an effective therapeutic intervention to retard myopia progression has the potential for greater public health impact on the burden and morbidity from myopia than the few treatments for its complications currently at hand.

\section{Authors' affiliations}

SM Saw, Department of Community, Occupational and Family Medicine, National University of Singapore, 16 Medical Drive, Singapore 117597 Republic of Singapore

SM Saw, K-G Au Eong, The Eye Institute, National Healthcare Group, Tan Tock Seng Hospital, 11 Jalan Tan Tock Seng, Singapore 308433, Republic of Singapore

SM Saw, G Gazzard, K-G Au Eong, D T H Tan, Singapore Eye

Research Institute, 5th Level, SNEC, 11 Third Hospital Avenue, Singapore 168751, Republic of Singapore

SM Saw, G Gazzard, D T H Tan, Singapore National Eye Centre, 11

Third Hospital Avenue, Singapore 168751, Republic of Singapore

G Gazzard, The Institute of Ophthalmology, 11 -43 Bath Street, London ECIV 9EL, UK

D T H Tan, Department of Ophthalmology, Faculty of Medicine, National University of Singapore, 10 Kent Ridge Crescent, Singapore 119260, Republic of Singapore

\section{REFERENCES}

1 Donders FC. Die Anomalien der Refraction und Accommodation des Auges. 1866:279-379

2 Hirschberg J. The history of ophthalmology. The middle ages; the sixteenth and seventeenth centuries. West Germany, 1985;2:263-79.

3 Curtin BJ. The etiology of myopia. The myopias. Basic science and clinical management. Philadelphia: Harper and Row, 1985:222.

4 Mutti DO, Bullimore MA. Myopia: an epidemic of possibilities? Optom Vis Sci 1999;76:257-8.

5 Troilo D, Wallman J. The regulation of eye growth and refractive state: an experimental study of emmetropization. Vis Res 1991;31:1237-50.

6 Mutti DO, Zadnik K, Adams AJ. Myopia. The nature versus nurture debate goes on. Invest Ophthalmol Vis Sci 1996;37:952-7.

7 Laties AM, Stone RA. Some visual and neurochemical correlates of refractive development. Vis Neurosci 1991;7:125-8.

8 Stone RA, Lin T, Laties AM, et al. Retinal dopamine and form-deprivation myopia. Proc Natl Acad Sci 1989;86:704-6.

9 Troilo D, Nickla DL, Wildsoet CF. Form deprivation myopia in mature common marmosets (Callithrix jacchus). Invest Ophthalmol Vis Sci 2000:41:2043-9.

10 Hung LF, Crawford ML, Smith EL. Spectacle lenses alter eye growth and the refractive status of young monkeys. Nat Med 1995;1:761-5.

11 Wallman J. Nature and nurture of myopia. Nature 1994;371:201-2.

12 Wallman J, Wildsoet C, Xu A, et al. Moving the retina: choroidal modulation of refractive state. Vis Res 1995;35:37-50.

13 Ong E, Grice K, Held R, et al. Effects of spectacle intervention on the progression of myopia in children. Optom Vis Sci 1999;76:363-9.

14 Parssinen O, Hemminki E, Klemetti A. Effect of spectacle use and accommodation on myopic progression: final results of a three-year randomised clinical trial among schoolchildren. Br J Ophthalmol 1989;73:547-51

15 Goldschmidt E. Myopia in humans: can progression be arrested? Ciba Found Symp 1990;155:222-9.

16 Goss DA. Attempts to reduce the rate of increase of myopia in young people-a critical literature review. Am J Optom Physiol Optics 1982;59:828-41.

17 Tokoro T, Kabe S. Treatment of the myopia and the changes in optical components. Report II. Full or under correction of myopia by glasses. Acta Soc Ophthalmol Jpn 1965;69:140-4.

18 Grosvenor T, Goss DA. Role of the cornea in emmetropia and myopia. Optom Vis Sci 1998;75:132-45.

19 Leung JT, Brown B. Progression of myopia in Hong Kong Chinese schoolchildren is slowed by wearing progressive lenses. Optom Vis Sci 1999;76:346-54.

20 Warren GT. Myopia control and abatement. Opt J Rev Optom 1955:92:33-4.

21 Feinberg R. Bifocals for children-a survey. Optom Wkly 1959;50:2055-8

22 Grossman $\mathbf{H}$. Twenty years of experience in prescribing bifocals for young myopes. Opt J Rev Optom 1949;86:40.

23 Mandell RB. Myopia control with bifocal correction. Arch Am Acad Optom 1959;36:652-8.

24 Mantyiarvi MI. Predicting of myopia progression in school children. $J$ Pediatr Ophthalmol Strabismus 1985;22:71-5.

25 Miles PW. A study of heterophoria and myopia in children some of whom wore bifocal lenses. Am J Ophthalmol 1962:54:111-14.

26 Oakley KH, Young FA. Bifocal control of myopia. Am J Optom Physiol Optics 1975;52:758-64. 
27 Rosenberg T, Goldschmidt E. The onset and progression of myopia in Danish school children. Doc Ophthalmol Proc 1981;28:33-9.

28 Septon RD. Myopia among optometry students. Am J Optom Physiol Optics 1984:61:745-51.

29 Wick RE. The use of bifocals in myopia-a case report. Am J Optom Arch Am Acad Optom 1947;24:368-71

30 Fulk GW, Cyert LA. Can bifocals slow myopia progression? J Am Optom Assoc 1996;67:749-54.

31 Fulk GW, Cyert LA, Parker DE. A randomized trial of the effect of single-vision vs. bifocal lenses on myopia progression in children with esophoria. Optom Vis Sci 2000;77:395-401.

32 Grosvenor T, Perrigin DM, Perrigin J, et al. Houston Myopia Control Study: a randomized clinical trial. Part II. Final report by the patient care team. Am J Optom Physiol Opt 1987;64:482-98.

33 Jensen H. Myopia progression in young school children. A prospective study of myopia progression and the effect of a trial with bifocal lenses and beta blocker eye drops. Acta Ophthalmol 1991;200(suppl): 1-79.

34 Shih YF, Hsiao CK, Lin LK, et al. Effects of atropine and multi-focal glasses in controlling myopic progression. Myopia 2000: Proceedings of the VIII International Conference on Myopia. Boston. Boston: Conference on Myopia 2000:352-6.

35 Gwaizda J, Marsh-Tootle WL, Hyman L, et al. Baseline refractive and ocular component measures of children enrolled in the Correction of Myopia Evaluation Trial (COMET). Invest Ophthalmol Vis Sci 2002:43:314-21.

36 Hyman L, Gwaizda J, Marsh-Tootle WL, et al. The correction of myopia evaluation trial (COMET): design and baseline characteristics. Invest Ophthalmol Vis Sci 1999;40(suppl):754.

37 Haugwitz TV, Blodi FC. Hirschberg's history of ophthalmology. Optical instruments Postage stamps. West Germany, 1986; Vol 11;77.

38 Bradley DV, Fernandes A, Tigges $M$, et al. Diffuser contact lenses retard axial elongation in infant rhesus monkeys. Vis Res 1996;36:509-14.

39 Smith EL, Hung LF, Harwerth RS. Effects of optically induced blur on the refractive status of young monkeys. Vis Res 1994;34:293-301.

40 Dumbleton KA, Chalmers RL, Richter DB, et al. Changes in myopic refractive error with nine months' extended wear of hydrogel lenses with high and low oxygen permeability. Optom Vis Sci 1999;76:845-9.

41 Grosvenor T, Perrigin D, Perrigin J, et al. Rigid gas-permeable contact lenses for myopia control: effects of discontinuation of lens wear. Optom Vis Sci 1991;68:385-9.

42 Kemmetmuller H. Contact lenses versus spectacles in myopia. Contact Lens Med Bull 1972;5:14-17

43 Miller B. Can progressive myopia be prevented by contact lenses. Contacto 1962;6:196-9.

44 Nolan J. Myopia control with contact lenses. Contacto 1967;1 1:24-7.

45 Perrigin J, Perrigin D, Quintero S, et al. Silicone-acrylate contact lenses for myopia control: 3-year results. Optom Vis Sci 1990;67:764-9.

46 Stone J. Myopia control after contact lens wear. Br J Physiol Opt 1974;29:93-108.

47 Andreo LK. Long-term effects of hydrophilic contact lenses on myopia. Ann Ophthalmol 1990;22:224-27, 229.

48 Horner DG, Soni PS, Salmon TO, et al. Myopia progression in adolescent wearers of soft contact lenses and spectacles. Optom Vis Sci 1999;76:474-9

49 Morrison RJ. Contact lenses and the progression of myopia. Optom Weekly 1956:47: 1487-8.

50 Grosvenor T, Perrigin D, Perrigin J, et al. Do rigid gas permeable contact lenses control the progress of myopia? Spectrum 1991:29-35

51 Khoo CY, Chong J, Rajan U. A 3-year study on the effect of RGP contact lenses on myopic children. Singapore Med J 1999;40:230-7.

52 Pose KA, Brand RJ, Vastine DW, et al. Corneal change accompanying orthokeratology. Plastic or elastic? Arch Ophthalmol 1983;101:1873-8.

53 Otsuka J, Kondo M. The experimental study of the influence of continuous contraction or relaxation of the ciliary muscle on the refraction. Acta Soc Ophthalmol Jpn 1950;54:182.

54 Saito $\mathbf{H}$. A histopathological study of experimental myopia: changes in ape's eyes, after long-term use of tropical atropine and pilocarpine. Acto Soc Ophthalmol Jpn 1979;67:237

55 Stone RA, Lin T, Laties AM. Muscarinic antagonist effects on experimental chick myopia. Exp Eye Res 1991;52:755-8.

56 Schwahn HN, Kaymak H, Schaeffel F. Effects of atropine on refractive development, dopamine release, and slow retinal potentials in the chick. Vis Neurosci 2000;17:165-76.

57 Taylor BJ, Smith PJ, Brook CG. Inhibition of physiological growth hormone secretion by atropine. Clin Endorinol 1985:22:497-501.

58 Casanueva FF, Villanueva L, Diaz Y, et al. Atropine selectively blocks GHRH-induced $\mathrm{GH}$ secretion without altering $\mathrm{LH}, \mathrm{FSH}, \mathrm{TSH}, \mathrm{PRL}$ and $\mathrm{ACTH} /$ cortisol secretion elicited by their specific hypothalamic releasing factors. Clin Endocrinol 1986;25:319-23.

59 Bedrossian RH. The effect of atropine on myopia. Ophthalmology 1979;86:713-19.

60 Chou AC, Shih YF, Ho TC, et al. The effectiveness of $0.5 \%$ atropine in controlling high myopia in children. J Ocul Pharmacol Ther 1997; 13:61-7.

61 Dyer JA. The role of cycloplegics in progressive myopia. Ophthalmology 1979;86:692.

62 Sampson WG. Role of cycloplegia in the management of functional myopia. Ophthalmology 1979;86:695-7.
63 Sato T. Long period of observation of the ocular refraction after instilling atropine. Acta Soc Ophthalmol Jpn 1943;47:23

64 Kao SC, Lu HY, Liu JH. Atropine effect on school myopia. A preliminary report. Acta Ophthalmol 1988;185(suppl):132-3.

65 Kennedy RH, Dyer JA, Kennedy MA, et al. Reducing the progression of myopia with atropine: a long term cohort study of olmsted county students. Binocul Vis Strabismus Q 2000;15:281-304.

66 Garston MJ. A closer look at diagnostic drugs for optometric use. J Am Optom Assoc 1975;46:39-43.

67 Gimbel HV. The control of myopia with atropine. Can J Ophthalmo 1973;8:527

68 Shih YF, Chen $\mathrm{CH}$, Chou AC, et al. Effects of different concentrations of atropine on controlling myopia in myopic children. J Ocul Pharmacol Ther 1999;15:85-90.

69 Yen MY, Liu JH, Kao SC, et al. Comparison of the effect of atropine and cyclopentolate on myopia. Ann Ophthalmol 1989;21:180-2, 187.

70 Gupta N, McAllister R, Drance SM, et al. Muscarinic receptor M1 and M2 subtypes in the human eye: QNB, pirenzipine, oxotremorine, and AFDX-1 16 in vitro autoradiography. Br J Ophthalmol 1994;78:555-9.

71 Rickers M, Schaeffel F. Dose-dependent effects of intravitreal pirenzepine on deprivation myopia and lens-induced refractive errors in chickens. Exp Eye Res 1995:61:509-16.

72 Mallorga P, Babilon RW, Buisson S, et al. Muscarinic receptors of the albino rabbit ciliary process. Exp Eye Res 1998;48:509-22.

73 Woldemussie E, Feldmann BJ, Chen J. Characterization of muscarinic receptors in cultured human iris sphincter and ciliary smooth muscle cells. Exp Eye Res 1993;56:385-92.

74 Zhang X, Hernandez MR, Yang HM, et al. Expression of muscarinic receptor subtype mRNA in the human ciliary muscle. Invest Ophthalmol Vis Sci 1995;36:1645-57.

75 Leech EM, Cottriall CL, McBrien NA. Pirenzepine prevents form deprivation myopia in a dose dependent manner. Ophthalmic Physiol Opt 1995;15:351-6.

76 Cottriall CL, McBrien NA. The M1 muscarinic antagonist pirenzepine reduces myopia and eye enlargement in the tree shrew. Invest Ophthalmol Vis Sci 1996;37:1368-79.

77 Cottriall CL, McBrien NA, Annies R, et al. Prevention of form-deprivation myopia with pirenzepine: a study of drug delivery and distribution. Ophthalmic Physiol Opt 1999;19:327-35.

78 Shedden AH, Sciberras D, Hutzelmann J, et al. Tolerability of pirenzepine ophthalmic solution in adult male volunteers. Invest Ophthalmol Vis Sci 1998;39(suppl):279.

79 Bartlett JD, Niemann K, Houde B, et al. Safety and tolerability of pirenzepine ophthalmic gel in pediatric, myopia patients. Invest Ophthalmol Vis Sci 2000;41(suppl):303.

80 Hosaka A. Myopia prevention and therapy. The role of pharmaceutical agents. Japanese studies. Acta Ophthalmol 1988;185(suppl):130-1

81 Schwartz JT. Results of a monozygotic cotwin control study on a treatment for myopia. Prog Clin Biol Res 1981;69:249-58.

82 Yolton DP, Kandel JS, Yolton RL. Diagnostic pharmaceutical agents: side effects encountered in a study of 15,000 applications. J Am Optom Assoc 1980;51:113-17.

83 Seltner RL, Weerheim JA, Sivak JG. Role of the lens and vitreous humor in the refractive properties of the eyes of three strains of goldfish. Vis Res 1989;29:681-5.

84 Pruett RC. Progressive myopia and intraocular pressure: what is the linkage? A literature review. Acta Ophthalmol 1988;185:117-27.

85 Cassidy L, Delaney Y, Fitzpatrick P, et al. Effect of accommodation on intraocular pressure in glaucomatous eyes. Ir J Med Sci 1998; 167:17-18.

86 Mauger RR, Likens CP, Applebaum M. Effects of accommodation and repeated applanation tonometry on intraocular pressure. Am J Optom Physiol Opt 1984;61:28-30.

87 Blake J, Horgan T, Carroll P, et al. Effect of accommodation of the lens on ocular pressure. Ir J Med Sci 1995;164:269-70.

88 Edwards $M H$, Chun CY, Leung SS. Intraocular pressure in an unselected sample of 6- to 7-year-old Chinese children. Optom Vis Sci 1993;70:198-200

89 Quinn GE, Berlin JA, Young TL, et al. Association of intraocular pressure and myopia in children. Ophthalmology 1995;102:180-5.

90 Gilmartin B, Hogan RE, Thompson SM. The effect of timolol maleate on tonic accommodation tonic vergence and pupil diameter. Invest Ophthalmol Vis Sci 1984;25:763-70.

91 Gilmartin B, Hogan RE. The relationship between tonic accommodation and ciliary muscle innervation. Invest Ophthalmol Vis $\mathrm{Sci}$ 1985:26:1024-8.

92 Katz IM, Hubbard WA, Getson AN, et al. Intraocular pressure decrease in normal volunteers following timolol ophthalmic solution. Invest Ophthalmol Vis Sci 1976;15:489-92.

93 Goldschmidt E, Jensen H., Maruschak D, et al. Can timolol maleate reduce the progression of myopia. Acta Ophthalmol (Copenh) 1985;63:90

94 Wiener $\mathbf{M}$. The use of epinephrin in progressive myopia. Am J Ophthalmol 1931;14:520-2.

95 Sica DA. Current concepts of pharmacotherapy in hypertensionophthalmically administered beta blockers and their cardiopulmonary effects. J Clin Hypertens $2001 ; 3: 175-8$.

96 Waldock A, Snape J, Graham CM. Effects of glaucoma medications on the cardiorespiratory and intraocular pressure status of newly diagnosed glaucoma patients. Br J Ophthalmol 2000;84:710-13. 
97 Bates WH. The Bates method for better eyesight without glasses. New York: Henry Holt, 1946

98 Angi MR, Caucci S, Pilotto E, et al. Changes in myopia, visual acuity, and psychological distress after biofeedback visual training. Optom Vis Sci 1996:73:35-42.

99 Trachtman JN. Biofeedback of accommodation to reduce myopia: a review. Am J Optom Physiol Opt 1987;64:639-43.

100 Daubs J, Shotwell AJ. Optical prophylaxis for environmental myopia: an epidemiological assesssment of short-term effects. Am J Optom Physiol Optics 1983:60:316-20.

101 Gallaway M, Pearl SM, Winkelstein AM, et al. Biofeedback training of visual acuity and myopia: a pilot study. Am J Optom Physiol Opt 1987;64:62-71

102 Gil KM, Collins FL Jr, Odom JV. The effects of behavioral vision training on multiple aspects of visual functioning in myopic adults. J Behav Med 1986;9:373-87.

103 Koslowe KC, Spierer A, Rosner M., et al. Evaluation of accommotrac biofeedback training for myopia control. Optom Vis Sci $1991 ; 68: 338-43$.
104 Rosen RC, Schiffman HR, Meyers H. Behavioral treatment of myopia: refractive error and acuity changes in relation to axial length and intraocular pressure. Am J Optom Physiol Optics 1984;61: 100-5.

105 Rupolo G, Angi M, Sabbadin E, et al. Treating myopia with acoustic biofeedback: a prospective study on the evolution of visual acuity and psychological distress. Psychosom Med 1997;59:313-17.

106 Rajan U, Tan FT, Chee D, et al. Accupressure point massage for myopia VII International Conference on Myopia Program and Abstracts. Taipei, Taiwan. Myopia International Research Foundation, 57, 1998.

107 Shih YF, Lin LL, Hwang CY, et al. The effects of Qi-Qong ocular exercise on accommodation. Chin J Physiol 1995;38:35-42.

108 Liu H, Lu Y, Dong Q, et al. Treatment of adolescent myopia by pressure plaster of semen impatientis on otoacupoints. J Trad Chin Med $1994 ; 14: 283-6$

109 Saw SM, Chan E, Koh A, et al. Interventions to retard myopia progression in children: an evidence-based update. Ophthalmology 2002;109:415-21

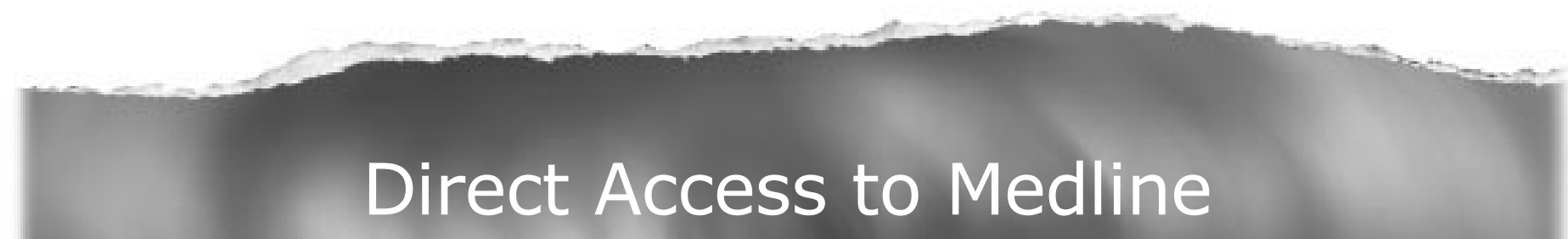

Medline

Link to Medline from the homepage and get straight into the National Library of Medicine's premier bibliographic database. Medline allows you to search across 9 million records of bibliographic citations and author abstracts from approximately 3,900 current biomedical journals.

www.bjophthalmol.com 